\title{
The Effect of Clozapine on Caudate Nucleus Volume in Schizophrenic Patients Previously Treated with Typical Antipsychotics
}

Floortje E. Scheepers, M.D., Christine C. Gispen de Wied, M.D., Ph.D., Hilleke E. Hulshoff Pol, Ph.D., Wiesje van de Flier, Jeroen A. van der Linden, M.D., and René S. Kahn, M.D., Ph.D.

Typical antipsychotics have been reported to enlarge the caudate nucleus in schizophrenic patients. The atypical antipsychotic, clozapine, is associated with a decrease in caudate size in patients previously treated with typical antipsychotics. The present study investigates whether a change in caudate volume after switching from treatment with typical antipsychotics to treatment with clozapine is related to improvement in symptoms or tardive dyskinesia (TD).

Twenty-six schizophrenic patients participated in this open study. Caudate nucleus volume and TD were assessed before discontinuing typical antipsychotics and after 24 weeks of treatment with clozapine. After discontinuing typical antipsychotics, symptoms were assessed in a 3 days drug-free period and subsequently once a month. Treatment with clozapine resulted in a decrease in caudate volume, improvement in symptoms and amelioration of TD. However, no difference in caudate volume changes was found between responders and non-responders to clozapine and no correlations were found between caudate volume changes and reduction of $T D$. In conclusion, this study replicates earlier findings that clozapine decreases caudate volume in patients previously treated with typical antipsychotics and suggests that this effect is unrelated to treatment response or to amelioration of TD. [Neuropsychopharmacology 24:47-54, 2001] (C) 2000 American College of Neuropsychopharmacology. Published by Elsevier Science Inc.
KEY WORDS: Schizophrenia; Caudate nucleus; Clozapine; MRI

Morphological changes in brain structures are extensively reported in schizophrenia (for reviews see McKenna 1987; Reynolds 1983; Buchsbaum 1990; McCarley et al. 1999; Westmoreland Corson et al. 1999a). Among them, enlargement of the caudate nucleus, as part of the basal ganglia, has been described several times (Jernigan et al. 1991; Mion et al. 1991; Breier et al. 1992; Swayze et al. 1992; Buchanan et al. 1993; Chakos et al. 1994, 1995; Hokama et al. 1995; Keshavan et al.

From the Department of Psychiatry, University Medical Center, Utrecht, The Netherlands.

Address correspondence to: Dr. Floortje E. Scheepers, Department of Psychiatry (A00.241), University Medical Center, PO Box 85500, 3508 GA Utrecht, The Netherlands.

Received 19 October 1999; revised 15 June 2000; accepted 5 July 2000.
1995; Ohnuma et al. 1997). Since decreased thalamic, hippocampal and superior temporal gyral volume have been associated with specific symptoms in schizophrenia (Barta et al. 1990; Bogerts et al. 1990, 1993; Friston et al. 1992: Shenton et al. 1992; Flaum et al. 1995) and the caudate nucleus receives neuronal projections from these regions (for reviews see Alexander and Crutcher 1990; Graybiel 1990), one could speculate that caudate volume may be related to certain aspects of patient functioning in schizophrenia as well. Indeed, the basal ganglia are involved in higher cognitive functions (Schneider 1984; Phillips and Carr 1987; Alexander et al. 1990; for reviews see Chevalier and Deniau 1990; Goldman-Rakic and Selemon 1990).

In Huntington or Parkinson disease patients, pathological changes of the caudate have been related to cognitive and behavioral disturbances as well as movement disorders, particularly tardive dyskinesia (TD) 
(Denny Brown and Yanagisawa 1976; Selemon and Goldman Rakic 1990; Graybiel 1990, 1997), phenomena that are also observed in some never medicated schizophrenic patients (Cassady et al. 1998; McCreadie and Ohaeri 1994; Fenton et al. 1994; Caligiuri and Lohr 1994; Lidsky 1997; Kraepelin 1919; for review see Busatto and Kerwin 1997).

Several neuroanatomical and physiological studies (Francis 1979; Serby and Goodgold 1986; Braff and Geyer 1990; Jernigan et al. 1991; Mion et al. 1991; Swayze et al. 1992; Heckers et al. 1991; Heckers 1997; Keshavan et al. 1998; Westmoreland Corson et al. $1999 b)$ support the hypothesis that the striatum, including the caudate nucleus, is involved in the pathophysiology of schizophrenia and/or TD. Assuming that an increase of basal ganglia volume in schizophrenia can be directly or indirectly attributed to the disease process, this finding has been interpreted as a consequence of a delay in programmed synaptic elimination (Feinberg 1982; Jernigan et al. 1991; Swayze et al. 1992) or as a compensatory response to a decreased input from anterior temporal lobe, frontal, mesolimbic, or thalamic regions (Swayze et al. 1992; Stevens 1992).

Interestingly, the changes in brain morphology may not be solely attributable to the disease process. Data are accumulating linking morphological abnormalities in schizophrenia with treatment with antipsychotic medication. Indeed, typical and atypical antipsychotics may produce different effects on brain morphology. For instance, typical antipsychotic use increases the size of the caudate nucleus (Chakos et al. 1994; Keshavan et al. 1994), whereas clozapine, following typical antipsychotic use, is associated with a decrease in the volume of the caudate nucleus (Chakos et al. 1995; Frazier et al. 1996; Westmoreland Corson et al. 1999a).

The effect of typical antipsychotics on caudate volume may be the result of a dopamine D1 and dopamine D2 receptor blockade which causes activation, regeneration, and hypertrophy of striatal synaptic and/or cellular elements and increase of bloodflow in the basal ganglia (Muller and Seeman 1977; Benes et al. 1983; Klintzova et al. 1989; Meshul and Casey 1989; Stevens 1992; Miller et al. 1997). The decrease in caudate size after switching to clozapine could then be the consequence of its weaker binding to D1 and D2 receptors as compared to typical antipsychotics (Hyttel et al. 1985).

Changes in brain morphology after antipsychotic treatment suggest that some neuroanatomical abnormalities in schizophrenia are dynamic or may be reversible rather than static or irreversible. One could speculate whether the effect of clozapine on caudate size following typical antipsychotic treatment is related to the well-documented clinical effect of clozapine or its beneficial effect on TD (Juul Povlsen et al. 1985; Casey 1989; Kane et al. 1988; Meltzer et al. 1989; Miller et al. 1994; Lindenmayer et al. 1994; Spivak et al. 1997).
Therefore, the present study attempts to replicate earlier studies on morphological changes in caudate volume after switching from typical antipsychotics to clozapine in a larger sample $(n=26)$ and investigates whether these changes are related to improvement of symptoms and amelioration of TD.

\section{METHODS}

\section{Subjects}

Twenty-six patients, treated in the University Medical Center in Utrecht, participated in this open design study (twenty-nine patients were included; one patient dropped out because of leucopenia and two patients discontinued because they needed other psychotropic medication). Eighteen male and eight female subjects with a mean age of 35.23 years (SD 10.34) and a mean duration of illness of 159.5 months (SD 114.1) were included in the study. All but two were right-handed. Upon entry into the study, patients were evaluated using the Comprehensive Assessment for Symptoms and History (CASH)-interview (Andreasen et al. 1992) and met DSM IV criteria for schizophrenia: paranoid type $(n=20)$, disorganised type $(n=2)$, undifferentiated type $(n=2)$, and residual type $(n=2)$.

Patients with organic brain disorder, alcohol or drug abuse according to DSM IV criteria, serious medical illness, or having been on depot medication within two months prior to the study were excluded from participation. All subjects were previously treated with at least one typical antipsychotic for a minimum of four weeks [mean duration of treatment 109.6 months (SD 102.0), mean life time dose chlorpromazine equivalent $527.02 \mathrm{mg}$ per day (SD 365.69)] (see Table 1). They all had failed to show adequate responses to treatment with typical antipsychotics [clinical global impression scale $(\mathrm{CGI})>4$ ] or had severe extrapyramidal side effects or TD prior to entry into the study.

The study has been approved by the ethics committee of the University Hospital and written informed consent was obtained from all subjects.

\section{Assessment}

Psychopathology, duration of illness, number and duration of previous hospitalizations, and prior medication history were assessed using the CASH interview and the CGI. Patients were withdrawn from their antipsychotic medication over a period of 2-7 days and remained free of antipsychotic medication for three days. Clozapine was then started at $25 \mathrm{mg} /$ day and increased gradually by $25-50 \mathrm{mg} /$ day to a minimum of $200 \mathrm{mg} /$ day and a maximum dose of $600 \mathrm{mg} /$ day. During the drug-free period patients were hospitalized [mean duration of hospitalization 8.35 weeks (SD 5.63)] and after 
Table 1. Use of Typical Antipsychotics in Individual Patients

\begin{tabular}{|c|c|c|c|c|}
\hline $\begin{array}{l}\text { Patient } \\
\text { number }\end{array}$ & Age & Sex & $\begin{array}{c}\text { Typical } \\
\text { antipsychotic } \\
\text { use in months }\end{array}$ & Doseyears $^{\mathrm{a}}$ \\
\hline 1 & 20 & $\mathrm{M}$ & 1.5 & 0.63 \\
\hline 2 & 34 & M & 32 & 8.13 \\
\hline 3 & 45 & $\mathrm{M}$ & 99 & 23.51 \\
\hline 4 & 46 & $\mathrm{M}$ & 276 & 115.00 \\
\hline 5 & 43 & $\mathrm{M}$ & 10 & 4.17 \\
\hline 6 & 29 & $\mathrm{M}$ & 1 & 0.42 \\
\hline 7 & 35 & $\mathrm{~F}$ & $145^{\mathrm{b}}$ & 51.96 \\
\hline 8 & 36 & $\mathrm{M}$ & 68 & 9.92 \\
\hline 9 & 21 & $\mathrm{M}$ & 34 & 7.08 \\
\hline 10 & 28 & $\mathrm{~F}$ & 22 & 8.71 \\
\hline 11 & 47 & F & 129 & 51.06 \\
\hline 12 & 32 & $\mathrm{~F}$ & 48 & 10.00 \\
\hline 13 & 55 & F & 276 & 94.30 \\
\hline 14 & 26 & $\mathrm{M}$ & 12 & 5.00 \\
\hline 15 & 39 & $\mathrm{~F}$ & 181 & 54.30 \\
\hline 16 & 29 & $\mathrm{M}$ & $102^{\mathrm{b}}$ & 12.75 \\
\hline 17 & 43 & $\mathrm{M}$ & 192 & 48.80 \\
\hline 18 & 31 & $\mathrm{M}$ & 96 & 75.00 \\
\hline 19 & 47 & $\mathrm{M}$ & $336^{\mathrm{b}}$ & 280.00 \\
\hline 20 & 19 & $\mathrm{M}$ & $12^{\mathrm{b}}$ & 2.50 \\
\hline 21 & 26 & $\mathrm{M}$ & $6^{\mathrm{b}}$ & 4.68 \\
\hline 22 & 26 & $\mathrm{~F}$ & 132 & 51.70 \\
\hline 23 & 23 & $\mathrm{M}$ & 16 & 4.87 \\
\hline 24 & 53 & $\mathrm{M}$ & $300^{\mathrm{b}}$ & 468.75 \\
\hline 25 & 41 & $\mathrm{~F}$ & $142^{\mathrm{b}}$ & 59.17 \\
\hline 26 & 42 & $\mathrm{M}$ & 180 & 150.00 \\
\hline
\end{tabular}

${ }^{\mathrm{a}} 1$ doseyear $=1$ year antipsychotic use of $100 \mathrm{mg}$ chlorpromazine equivalent/day (for methods see Schultz et al. 1995).

${ }^{\mathrm{b}}$ Depot medication in history.

adjustment to clozapine they were treated as outpatients.

Patients were treated for six months in an open design, the dose being adjusted for optimal clinical improvement [mean dose of clozapine $345.57 \mathrm{mg}$ per day (SD 63.44)]. Compliance was assessed by clozapine plasma levels measured once a month. Benzodiazepines up to a maximum daily dose of $20 \mathrm{mg}$ diazepam equivalents and chloralhydrate up to $1500 \mathrm{mg} /$ day were allowed throughout the study. Four patients used a daily dose of $2.5-20 \mathrm{mg}$ diazepam equivalents during the first 2-6 weeks of treatment with clozapine. No other psychotropic medications were allowed.

Before discontinuing typical antipsychotics (baseline) and after 24 weeks of treatment with clozapine, neuroanatomical variables were assessed using Magnetic Resonance Imaging (MRI), and TD was rated using the Simpson scale (Simpson et al. 1979). Psychopathology was rated on the last drug-free day, bi-weekly for the first eight weeks of clozapine use, and subsequently once a month using the Positive and Negative Symptom Scale (PANSS) (Kay et al. 1987) and the CGI. The PANSS interview was performed by two raters who independently scored the items and afterwards achieved consensus.

\section{Magnetic Resonance Images (MRI)}

MRI were obtained on a whole body 1.5 Tesla Philips Gyroscan NT, using a standard proton head coil operating at $64 \mathrm{MHz}$. For analysis of the caudate nucleus a T1weighted scan with $1.2 \mathrm{~mm}$ contiguous coronal slices $\left(\mathrm{TE}=4.6 \mathrm{~ms} ; \mathrm{TR}=30 \mathrm{~ms}\right.$; flip angle $30^{\circ} ; \mathrm{FOV}=256 /$ $80 \%$ ) of the whole head was used.

The MRI data were processed on a Unix 9000 series workstation. All scans were blinded with respect to medication use (typical antipsychotic or clozapine) and any identifying characteristics, including side (in 50\% of the scans the left-right axis were exchanged). Images were put into Talairach frame and corrected for scanner nonuniformity. The caudate nucleus was measured manually. The head and body of the caudate nuclei were identified and delineated slice by slice in an anterior-posterior direction using ANALYZE ${ }^{\mathrm{TM}}$ (Mayo Clinic, Rochester, MN).

Segmentation started in the first slice the caudate nucleus was clearly visible. Its medial border was the lateral ventricle. Laterally, it was limited by the internal capsule, excluding the interconnecting gray matter striae between caudate and putamen visible in the internal capsule (the pontes grisei caudatolenticulares). Posteriorly, the last slice in which the caudate nucleus was segmented was the slice before the one in which the posterior commisure was clearly visible. Its inferior border was defined as follows: anterior, by the white matter connecting the rostrus corporis callosi and the capsula externa, as visible in the coronal view below the caudate nucleus. Then, from the first slice, where the putamen is clearly visible until the slice anterior to the slice in which the anterior commissure crosses the midline, the nucleus accumbens was separated from the caudate by a line from the most inferior point of the lateral ventricle to the most inferior point of the internal capsule (adapted from Chakos et al. 1994).

The reliability of the measurements was determined by the intraclass correlation coefficient (ICC) based on 10 brains. The interrater reliability was 0.98 for the left caudate nucleus and 0.97 for the right caudate nucleus.

\section{Data Analysis}

Analysis of the caudate nucleus size and total brain volume was performed using repeated measures analysis of variance (ANOVA) with the factors 'side' (right and left), 'treatment' (status during last week of treatment with typical antipsychotics versus status after 24 weeks of treatment with clozapine), and 'group' (responders and nonresponders). Patients were divided into responders $(n=13)$ and nonresponders $(n=13)$ based on 


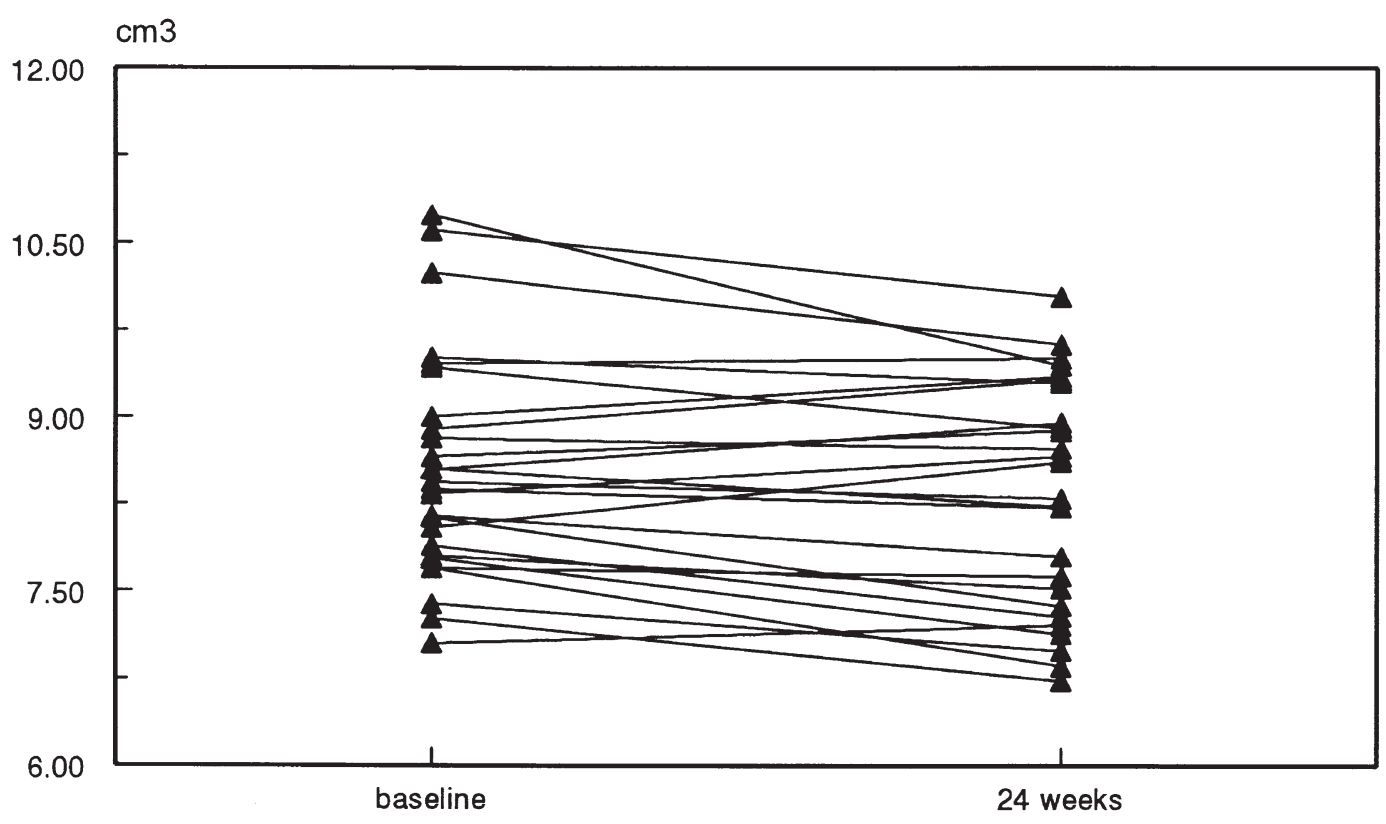

Figure 1. Individual changes in caudate nucleus volume after switching from typical antipsychotics (baseline) to clozapine (24 weeks).

a priori criteria of a total PANSS reduction of at least $20 \%$ from pre-clozapinetreatment scores.

ANOVA repeated measures analysis with the factor 'time' (seven levels; 0, 2, 4, 8, 12, 16, 20, and 24 weeks) was used to analyse treatment response as scored by the PANSS and CGI. A paired t-test was performed to analyse a change in the presence of TD. Pearson correlations were calculated to examine the relationship between caudate volume changes [ $\Delta$ caudatus $=($ caudatus $_{24 \text { weeks }}-$ caudatus $\left._{\text {baseline }}\right) /$ caudatus $_{\text {baseline }} \times 100 \%$ ] following clozapine use and degree of psychiatric symptom improvement $\left[\Delta \mathrm{PANSS}=\left(\mathrm{PANSS}_{24 \text { weeks }}-\right.\right.$ PANSS $_{\text {last drug-free day }} /$ PANSS $_{\text {last drug-free day }} \times 100 \%$ ] and / or degree of $\mathrm{TD}$ amelioration $\left[\Delta \mathrm{TD}=\left(\mathrm{TD}_{24 \text { weeks }}-\right.\right.$ $\left.\mathrm{TD}_{\text {baseline }}\right) / \mathrm{TD}_{\text {baseline }} \times 100 \%$.

\section{RESULTS}

Clozapine use was associated with a significant reduction in caudate volume $(\mathrm{DF}=23 ; \mathrm{F}=5.3 ; p<.05 ;$ mean caudate volume at baseline: $8.49 \pm 0.93 \mathrm{~cm}^{3}$; after 24 weeks of clozapine treatment: $8.27 \pm 0.97 \mathrm{~cm}^{3}$ ). A treatment $\times$ side interaction was not observed $(\mathrm{DF}=23 ; \mathrm{F}=$ $0.16 ; p=.7)$. No differences in caudate volume were found between responders and nonresponders (treatment $\times$ group, $\mathrm{DF}=23 ; \mathrm{F}=0.95 ; p=.34$ ) (see Figure 1 for details on individual changes). No significant changes were found in total brain volume (DF $=22$; $\mathrm{F}=3.85 ; p=.062$ ).

Patients significantly improved during treatment with clozapine as was demonstrated by lower scores on the PANSS and CGI over time (PANSS: DF $=8 ; \mathrm{F}=$ 2.95; $p<.05 ; \mathrm{CGI}: \mathrm{DF}=8 ; \mathrm{F}=15 ; p<.0001$ ) (see Figure $2)$. Likewise, the severity of TD was significantly reduced during clozapine treatment $(\mathrm{t}=3.67$; $\mathrm{DF}=14$; $p<.01)$. However, no significant correlations were observed between caudate volume changes and improvement in total PANSS $(\mathrm{r}=0.06 ; p=.77)$, positive symptoms $(\mathrm{r}=0.26 ; p=.22)$, negative symptoms $(\mathrm{r}=-0.28$; $p=.17)$, CGI $(\mathrm{r}=0.11 ; p=.64)$ or TD $(\mathrm{r}=-0.08 ; p=$ .79). Also, no significant correlations were found between caudate volume change and duration $(r=0.24$; $p=.26)$ or doses $(\mathrm{r}=-0.01 ; p=.97)$ of treatment with typical antipsychotics.

\section{DISCUSSION}

This study investigated whether a change in caudate volume, after switching from treatment with typical antipsychotics to clozapine, was related to improvement of symptoms and amelioration of TD in schizophrenia. Replacing typical antipsychotics with clozapine resulted in a significant decrease of caudate nucleus volume which was not significantly correlated with improvement of symptoms or amelioration of TD.

This open study replicated previous findings associating treatment with clozapine to caudate volume reduction (Chakos et al. 1995; Frazier et al. 1996; Westmoreland Corson et al. 1999a), symptom improvement (Juul 


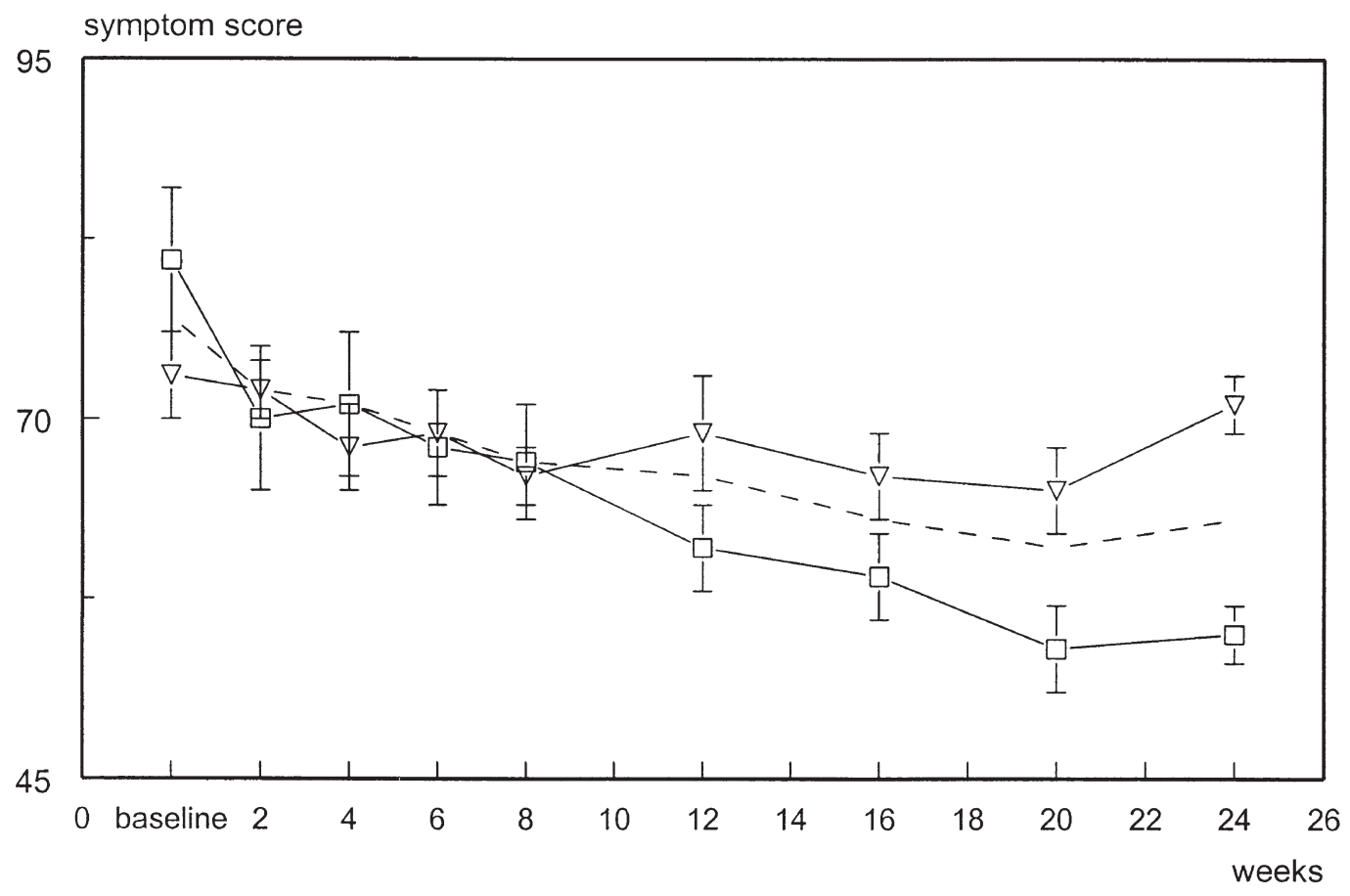

Figure 2. PANSS scores $( \pm$ SD) during treatment with clozapine in all subjects $(n=26$; - $)$, responders $(n=13$; $\square)$, and nonresponders $(n=13 ; \nabla)$.

Povlsen et al. 1985; Meltzer et al. 1989; Miller et al. 1994; Lindenmayer et al. 1994; Kane et al. 1988), and TD amelioration (Casey 1989; Spivak et al. 1997). Whether the effect of clozapine on caudate nucleus volume is of clinical relevance was never investigated.

The basal ganglia play a part in higher cognitive functions (Schneider 1984; Phillips and Carr 1987; Alexander et al. 1990; for reviews see Chevalier and Deniau 1990; Goldman-Rakic and Selemon 1990). In previous studies, increased caudate volumes in schizophrenia were associated with poorer neuropsychological test performance on finger tapping and Hebb's Recurring Digits (Hokama et al. 1995) and cognitive impairment (Bilder et al. 1993). A trend was found for the caudate nucleus to be larger in schizophrenic patients with deficit symptoms (Buchanan et al. 1993). Mion et al. (1991) found significantly smaller volumes of caudate nuclei in schizophrenic patients with TD as compared to patients without TD and normal controls whereas in rats, increased striatal size was associated with high-vacuous chewing movement syndrome (Chakos et al. 1998). Since 'volume' is correlated with 'symptoms' one could speculate that 'volume-change' is correlated with 'symptom-change'. The fact that this study found no significant correlations between caudate volume change and clinical improvement suggests that volume changes in the caudate nucleus may rather be considered a non-specific trophic effect of antipsychotic treat- ment than a therapeutical effect. The effect of clozapine on caudate volume may then be explained by its pharmacological properties. Typical antipsychotics block D2 receptors that are highly concentrated in the striatum (Tune et al. 1993; Volkow et al. 1996; Kufferle et al. 1996) and chronic treatment with typical antipsychotics is reported to increase the dopamine D2 receptor density in this brain structure (Sedvall et al. 1995; Seeman 1987; Joyce et al. 1988).

Clozapine may exert its dopamine antagonistic effect predominantly through blockade of D3 and D4 receptors (for review see Kinon and Lieberman 1996). These receptors are only weakly expressed in basal ganglia but instead mainly found in the limbic system and cerebral cortex. It has been suggested that, since clozapine has a lower level of D2 antagonism in striatum, this could result in a downregulation of D2 receptors in these structures with subsequent dystrophic reduction of the striatal area (Lee et al. 1999).

It remains unclear whether the decrease in caudate volume is an effect of clozapine per se or it is related to prior treatment with typical neuroleptics. Two studies suggest that a reduction in caudate size through clozapine is probably due to the drug itself: clozapine was associated with a decrease of $4.5 \%$ in basal ganglia volume in four medication-naive schizophrenic patients (Gunduz et al. 1998) and a decrease of the striatum volume, without prior treatment with typical agents, in 
rats (Lee et al. 1999). Unfortunately, extrapyramidal side effects were not assessed in this study which could be worth investigating in future research. Moreover, we investigated a treatment refractory sample of schizophrenic patients and thus results may be different in a more representative sample.

To conclude, this study replicates earlier findings that clozapine decreases the caudate volume in patients previously treated with typical antipsychotics and suggests that this effect is independent of treatment response.

\section{REFERENCES}

Alexander GE, Crutcher MD, DeLong MR (1990): Basal ganglia-thalamocortical circuits: Parallel substrates for motor, oculomotor, prefrontal and limbic functions. Prog Brain Res 85:119-146

Alexander GE, Crutcher MD (1990): Functional architecture of basal ganglia circuits: Neural substrates of parallel processing. Trends Neurosci 13:266-270

Andreasen NC, Flaum M, Arndt S (1992): The Comprehensive Assessment of Symptoms and History (CASH). An instrument for assessing diagnosis and psychopathology. Arch Gen Psychiatry 49:615-623

Barta PE, Pearlson GD, Powers RE, Richards SS, Tune LE (1990): Auditory hallucinations and smaller superior temporal gyrus volume in schizophrenia. Am J Psychiatry 147:1457-1462

Benes FM, Paskevich PA, Domesick VB (1983): Haloperidolinduced plasticity of axon terminals in rat substantia nigra. Science 221:969-971

Bilder R, Chakos M, Lerner G, Bogerts B, Degreef G, Ashtari M, Lieberman J (1993): Cognitive deficit associated with increased caudate volume in schizophrenia. Biol Psychiatry 33:121

Bogerts B, Ashtari M, Degreef G, Alvir JMJ, Bilder RM, Lieberman JA (1990): Reduced temporal limbic structure volumes on magnetic resonance images in first episode schizophrenia. Psychiatry Res 35:1-13

Bogerts B, Lieberman JA, Ashtari M, Bilder RM, Degreef G, Lerner G, Johns C, Masiar S (1993): Hippocampusamygdala volumes and psychopathology in chronic schizophrenia. Biol Psychiatry 33:236-246

Braff DL, Geyer MA (1990): Sensorimotor gating and schizophrenia. Human and animal model studies. Arch Gen Psychiatry 47:181-188

Breier A, Buchanan RW, Elkashef A, Munson RC, Kirkpatrick B, Gellad F (1992): Brain morphology and Schizophrenia: A magnetic resonance imaging study of limbic, prefrontal cortex, and caudate structures. Arch Gen Psychiatry 49:921-926

Buchanan RW, Breier A, Kirkpatrick B, Elkashef A, Munson RC, Gellad F, Carpenter WT (1993): Structural abnormalities in deficit and nondeficit Schizophrenia. Am J Psychiatry 150:59-65

Buchsbaum MS (1990): The frontal lobes, basal ganglia, and temporal lobes as sites for schizophrenia. Schizophr Bull 16:379-389

Busatto GF, Kerwin RW (1997): Schizophrenia, psychosis, and the basal ganglia. Psychiatr Clin North Am 20:897910

Caligiuri MP, Lohr JB (1994): A disturbance in the control of muscle force in neuroleptic-naive schizophrenic patients. Biol Psychiatry 35:104-111

Casey DE (1989): Clozapine: Neuroleptic-induced EPS and tardive dyskinesia. Psychopharmacology (Berl) 99(Suppl): S47-S53

Cassady SL, Adami H, Moran M, Kunkel R, Thaker GK (1998): Spontaneous dyskinesia in subjects with schizophrenia spectrum personality. Am J Psychiatry 155:70-75

Chakos MH, Shirakawa O, Lieberman J, Lee H, Bilder R, Tamminga CA (1998): Striatal enlargement in rats chronically treated with neuroleptic. Biol Psychiatry 44:675-684

Chakos MH, Lieberman JA, Alvir J, Bilder R, Ashtari M (1995): Caudate nuclei volumes in schizophrenic patients treated with typical antipsychotics or clozapine. Lancet 345:456-457

Chakos MH, Lieberman JA, Bilder RM, Borenstein M, Lerner G, Bogerts B, Wu H, Kinon B, Ashtari M (1994): Increase in caudate nuclei volumes of first-episode schizophrenic patients taking antipsychotic drugs. Am J Psychiatry 151:1430-1436

Chevalier G, Deniau JM (1990): Disinhibition as a basic process in the expression of striatal function. Trends Neurosci 13:277-280

Denny Brown D, Yanagisawa N (1976): The role of the basal ganglia in the initiation of movement. Res Publ Assoc Res Nerv Ment Dis 55:115-149

Feinberg I (1982): Schizophrenia and late maturational brain changes in man. Psychopharmacol Bull 18:29-31

Fenton WS, Wyatt RJ, McGlashan TH (1994): Risk factors for spontaneous dyskinesia in schizophrenia. Arch Gen Psychiatry 51:643650

Flaum M, O'Leary DS, Swayze VW, Miller DD, Arndt S, Andreasen NC (1995): Symptom dimensions and brain morphology in schizophrenia and related psychotic disorders. J Psychiatric Res 29:261-276

Francis AF (1979): Familial basal ganglia calcification and schizophreniform psychosis. Br J Psychiatry 135:360362

Frazier JA, Giedd JN, Kaysen D, Albus K, Hamburger S, Alaghband Rad J, Lenane MC, McKenna K, Breier A, Rapoport JL (1996): Childhood-onset schizophrenia: Brain MRI rescan after 2 years of clozapine maintenance treatment. Am J Psychiatry 153:564-566

Friston KJ, Liddle PF, Frith CD, Hirsch SR, Frackowiak RSJ (1992): The left medial temporal region and schizophrenia. Brain 115:367-382

Goldman Rakic PS, Selemon LD (1990): New frontiers in basal ganglia research. Introduction. Trends Neurosci 13:241-244

Graybiel AM (1997): The basal ganglia and cognitive pattern generators. Schizophr Bull 23:459-469

Graybiel AM (1990): Neurotransmitters and neuromodulators in the basal ganglia. Trends Neurosci 13:244-254 
Graybiel AM, Hirsch EC, Agid Y (1990): The nigrostriatal system in Parkinson's disease. Adv Neurol 53:17-29

Gunduz H, Wu H, Ashtari M, Bogerts B, Robinson D, Becker J, Bilder R (1998): Abstracts of the Ninth Biennial Winter Workshop on Schizophrenia. Schizophrenia Res 29:80-81

Heckers S, Heinsen H, Heinsen Y, Beckman H (1991): Cortex, white matter, and basal ganglia in schizophrenia: A volumetric postmortem study. Biol Psychiatry 29:556566

Heckers S (1997): Neuropathology of schizophrenia: Cortex, thalamus, basal ganglia, and neurotransmitter-specific projection systems. Schizophr Bull 23:403-421

Hokama H, Shenton ME, Nestor PG, Kikinis R, Levitt JJ, Metcalf D, Wible CG, O'Donnell BF, Jolesz FA, McCarley RW (1995): Caudate, putamen, and globus pallidus volume in schizophrenia: A quantitative MRI study. Psychiatry Res 61:209-229

Hyttel J, Larsen JJ, Christensen AV, Arnt J (1985): Receptorbinding profiles of neuroleptics. Psychopharmacology 2(Suppl):9-18

Jernigan TL, Zisook S, Heaton RK, Moranville JT, Hesselink JR, Braff DL (1991): Magnetic resonance imaging abnormalities in lenticular nuclei and cerebral cortex in schizophrenia. Arch Gen Psychiatry 48:881-890

Joyce JN, Lexow N, Bird E, Winokur A (1988): Organization of dopamine D1 and D2 receptors in human striatum: Receptor autoradiographic studies in Huntington's disease and schizophrenia. Synapse 2:546-557

Juul Povlsen U, Noring U, Fog R, Gerlach J (1985): Tolerability and therapeutic effect of clozapine. A retrospective investigation of 216 patients treated with clozapine for up to 12 years. Acta Psychiatr Scand 71:176-185

Kane J, Honigfeld G, Singer J, Meltzer HY, Clozaril Collaborative Study Group (1988): Clozapine for the treatmentresistant schizophrenic: A double-blind comparison with chlorpromazine. Arch Gen Psychiatry 45:789-796

Kay SR, Fiszbein A, Opler LA (1987): The positive and negative syndrome scale (PANSS) for schizophrenia. Schizophr Bull 13:261-276

Keshavan MS, Bagwell WW, Haas GL, Sweeney JA, Schooler NR, Pettegrew JW (1994): Changes in caudate volume with neuroleptic treatment. Lancet 344:1434

Keshavan MS, Bagwell WW, Haas GL, Sweeney JA, Schooler NR, Pettegrew JW (1995): Does caudate volume increases during follow up in first-episode psychosis? Schizophr Res 15:87

Keshavan MS, Rosenberg D, Sweeney JA, Pettegrew JW (1998): Decreased caudate volume in neuroleptic-naive psychotic patients. Am J Psychiatry 155:774-778

Kinon BJ, Lieberman JA (1996): Mechanisms of action of atypical antipsychotic drugs: A critical analysis. Psychopharmacology (Berl) 124:2-34

Klintzova AJ, Haselhorst V, Uranova NA (1989): The effects of haloperidol on synaptic plasticity in rat's medial prefrontal cortex. J Hirnforsh 30:51-57

Kraepelin E (1919): Dementia praecox and paraphrenia. In Barclay RM (eds) (English translation reprinted 1971) Huntington, NY, Robert E. Krieger Publishing Co.

Kufferle B, Brucke T, Topitz Schratzberger A, Tauscher J, Gossler R, Vesely C, Asenbaum S, Podreka I, Kasper S
(1996): Striatal dopamine-2 receptor occupancy in psychotic patients treated with risperidone. Psychiatry Res 68:23-30

Lee H, Tarazi FI, Chakos M, Wu H, Redmond M, Alvir JM, Kinon BJ, Bilder R, Creese I, Lieberman JA (1999): Effects of chronic treatment with typical and atypical antipsychotic drugs on the rat striatum. Life Sci 64:1595-1602

Lidsky TI (1997): Neuropsychiatric implications of basal ganglia dysfunction. Biol Psychiatry 41:383-385

Lindenmayer JP, Grochowski S, Mabugat L (1994): Clozapine effects on positive and negative symptoms: A sixmonth trial in treatment-refractory schizophrenics. J Clin Psychopharmacol 14:201-204

McCarley RW, Wible CG, Frumin M, Hirayasu Y, Levitt JJ, Fischer IA, Shenton ME (1999): MRI anatomy of schizophrenia. Rev Biol Psychiatry 45:1099-1119

McCreadie RG, Ohaeri JU (1994): Movement disorder in never and minimally treated Nigerian schizophrenic patients. Br J Psychiatry 164:184-189

McKenna PJ (1987): Pathology, phenomenology and the dopamine hypothesis of schizophrenia. Br J Psychiatry 151:288-301

Meltzer HY, Bastani B, Kwon KY, Ramirez LF, Burnett S, Sharpe J (1989): A prospective study of clozapine in treatment-resistant schizophrenic patients. I. Preliminary report. Psychopharmacology (Berl) 99(Suppl):S68S72

Meshul CK, Casey DE (1989): Regional, reversible ultrastructural changes in rat brain with chronic neuroleptic treatment. Brain Res 489:338-346

Miller DD, Andreasen NC, O'Leary DS, Rezai K, Watkins GL, Ponto LL, Hichwa RD (1997): Effect of antipsychotics on regional cerebral blood flow measured with positron emission tomography [published erratum appears in Neuropsychopharmacology 1998 Apr;18(4):3234]. Neuropsychopharmacology 17:230-240

Miller DD, Perry PJ, Cadoret RJ, Andreasen NC (1994): Clozapine's effect on negative symptoms in treatmentrefractory schizophrenics. Compr Psychiatry 35:8-15

Mion CC, Andreasen NC, Arndt S, Swayze VW, Cohen GA (1991): MRI abnormalities in tardive dyskinesia. Psychiatry Res 40:157-166

Muller P, Seeman P (1977): Brain neurotransmitter receptors after long-term haloperidol: Dopamine, acetylcholine, serotonin, $\alpha$-noradrenergic and naloxone receptors. Life Sci 21:1751-1758

Ohnuma T, Kimura N, Takahashi T, Iwamoto N, Arai H (1997): A magnetic resonance imaging study in first episode disorganized-type patients with Schizophrenia. Psychiatry Clin Neurosci 51:9-15

Phillips AG, Carr GD (1987): Cognition and the basal ganglia: A possible substrate for procedural knowledge. Can J Neurol Sci 14:381-385

Reynolds GP (1983): Increased concentrations and lateral asymmetry of amygdala dopamine in schizophrenia. Nature 305:527-529

Schneider JS (1984): Basal ganglia role in behavior: Importance of sensory gating and its relevance to psychiatry. Biol Psychiatry 19:1693-1710 
Schultz SK, Miller DD, Arndt S, Ziebel S, Gupta S, Andreasen NC (1995): Withdrawal-emergent dyskinesia in patients with schizophrenia during antipsychotic discontinuation. Biol Psychiatry 38:713-719

Sedvall G, Pauli S, Farde L, Karlsson P, Nyberg S, Nordstrom AL (1995): Recent developments in PET scan imaging of neuroreceptors in schizophrenia. Isr J Psychiatry Relat Sci 32:22-29

Seeman P (1987): Dopamine receptors and the dopamine hypothesis of schizophrenia. Synapse 1:133-152

Selemon LD, Goldman Rakic PS (1990): Topographic intermingling of striatonigral and striatopallidal neurons in the rhesus monkey. J Comp Neurol 297:359-376

Serby M, Goodgold A (1986): Tardive dyskinesia-like disorder due to basal ganglia infarction. J Clin Psychopharmacol 6:122

Shenton ME, Kikinis R, Jolesz FA, Pollak SD, LeMay M, Wible CG, Hokama H, Martin J, Metcalf D, Coleman M (1992): Abnormalities of the left temporal lobe and thought disorder in schizophrenia: A quantitative magnetic resonance imaging study. N Engl J Med 327:604612

Simpson GM, Lee JH, Zoubok B, Gardos G (1979): A rating scale for tardive dyskinesia. Psychopharmacology (Berl) 64:171-179

Spivak B, Mester R, Abesgaus J, Wittenberg N, Adlersberg S, Gonen N, Weizman A (1997): Clozapine treatment for neuroleptic-induced tardive dyskinesia, parkinsonism, and chronic akathisia in schizophrenic patients. J Clin Psychiatry 58:318-322

Stevens JR (1992): Abnormal reinnervation as a basis for schizophrenia: A hypothesis. Arch Gen Psychiatry 49:238-243

Swayze VW, Andreasen NC, Alliger RJ, Yuh WTC, Ehrhardt JC (1992): Subcortical and temporal structures in affective disorder and schizophrenia: A magnetic resonance imaging study. Biol Psychiatry 31:221-240

Tune LE, Wong DF, Pearlson G, Strauss M, Young T, Shaya EK, Dannals RF, Wilson AA, Ravert HT, Sapp J, Cooper T, Chase GA, Wagner HN Jr (1993): Dopamine D2 receptor density estimates in schizophrenia: A positron emission tomography study with 11C-N-methylspiperone. Psychiatry Res 49:219-237

Volkow ND, Fowler JS, Gatley SJ, Logan J, Wang GJ, Ding YS, Dewey S (1996): PET evaluation of the dopamine system of the human brain. J Nucl Med 37:1242-1256

Westmoreland Corson P, Nopoulos P, Miller DD, Arndt S, Andreasen NC (1999a): Change in basal ganglia volume over 2 years in patients with schizophrenia: Typical versus atypical neuroleptics. Am J Psychiatry 156:12001204

Westmoreland Corson P, Nopoulos P, Andreasen NC, Heckel D, Arndt S (1999b): Caudate size in first-episode neuroleptic-naive schizophrenic patients measured using an artificial neural network. Biol Psychiatry $46: 712-720$ 